\title{
Inter-population variabilities in seed mass and germination of Panicum turgidum and Pennisetum divisum in the desert of Kuwait
}

\author{
Arvind BHATT ${ }^{1 *}$, Narayana R BHAT ${ }^{1}$, Afaf AL-NASSER ${ }^{1}$, María M CARÓN ${ }^{2}$, Andrea \\ SANTO $^{3}$
}

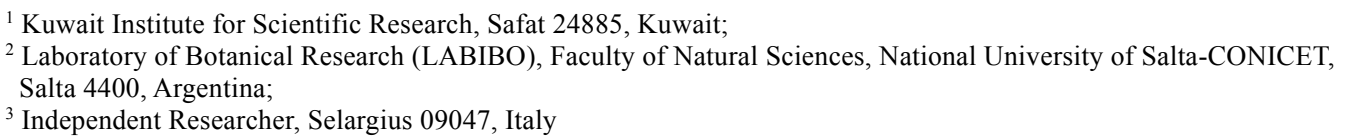

\begin{abstract}
Understanding variability in seed germination among populations is essential for planning an effective germplasm collection for restoration and conservation purposes. The knowledge of germination and dormancy patterns among populations of desert grasses is crucial for determining the potential of the species and populations to be used for restoration and conservation as well as forage production. Variability in seed germination of Panicum turgidum Forssk and Pennisetum divisum (Gmel.) Henr. in the desert of Kuwait was evaluated in different populations in May 2017. Experiment of seed germination (25 seeds and 4 replicates) was conducted for each population at night/day temperatures of $15^{\circ} \mathrm{C} / 20^{\circ} \mathrm{C}$ and $20^{\circ} \mathrm{C} / 30^{\circ} \mathrm{C}$ under the following light condition: continuous darkness or $12 \mathrm{~h} / 12 \mathrm{~h}$ light/dark. Results showed that seed masses of both species strongly varied according to their seed provenances, and both species produced heavier seeds in population with a higher soil electrical conductivity. Seed germination percentage considerably varied between two species, and the variation in $P$. turgidum was greater $(17 \%-49 \%)$ than that of $P$. divisum $(72 \%-93 \%)$. Germination percentage in P. turgidum was greater at high temperature $\left(20^{\circ} \mathrm{C} / 30^{\circ} \mathrm{C}\right)$ than at low temperature $\left(15^{\circ} \mathrm{C} / 20^{\circ} \mathrm{C}\right)$. However, temperature regimes had no effect on germination percentage of $P$. divisum seeds. Mean germination time of both species exhibited significant inter-population variability. This result is especially relevant to assure the selection of the best population of each species and the regeneration success of the species. Besides this, inter-population variability also provides valuable information for enhancing our understanding of the mechanisms that regulate seed germination and how they might be related to seed provenance.
\end{abstract}

Keywords: desert grass; seed germination; inter-population variability; seed provenance; seed dormancy

Citation: Arvind BHATT, Narayana R BHAT, Afaf AL-NASSER, María M CARÓN, Andrea SANTO. 2020. Inter-population variabilities in seed mass and germination of Panicum turgidum and Pennisetum divisum in the desert of Kuwait. Journal of Arid Land, 12(1): 144-153. https://doi.org/10.1007/s40333-019-0017-6

\section{Introduction}

Desert is very susceptible to land degradation due to the long-term dry season, low and irregular rainfall, poor soil water holding capacity, mobile surface deposit and sparse vegetation cover (Mganga et al., 2015). Moreover, overgrazing, off-road driving, camping, lack of enforcement for

\footnotetext{
*Corresponding author: Arvind BHATT (E-mail: drbhatt79@gmail.com)

Received 2018-10-08; revised 2018-11-14; accepted 2019-05-14

C Xinjiang Institute of Ecology and Geography, Chinese Academy of Sciences, Science Press and Springer-Verlag GmbH Germany, part of Springer Nature 2020
} 
implementing proper resource management policies, industrialization and urban development can cause biodiversity loss and ecosystem degradation due to the degradation of hydrological system and the loss of soil productivity (Al-Awadhi et al., 2003; Richer, 2008). Planting native plant species for vegetation rehabilitation, which are adapted to local environmental conditions, could be an effective way to restore the degraded desert ecosystems (Bhatt, 2013; Richer et al., 2016).

Variations in altitude, latitude, soil moisture, soil nutrient content, temperature, light and degree of habitat disturbance affect the maternal environmental conditions and consequently influence seed production, dormancy and germination, although the degree to how the maternal environmental conditions affect these phases is frequently species-specific (Baskin and Baskin, 2014; Carón et al., 2014; El-Keblawy et al., 2016, 2017). Therefore, to find out the potential seed resources for vegetation rehabilitation, we should research the inter-population variations in seed production, dormancy and germination from different seed provenances.

Grasses play important roles in animal nutrition and help in land stabilization by soil protection and sand dune fixation in desert (Bhatt et al., 2016) and they could be used for the restoration or rehabilitation in degraded rangelands (Osman et al., 2008). Selection of appropriate species is a key factor that determines the success of environmental restoration especially in desert environment (Phondani et al., 2016).

Panicum turgidum Forssk. and Pennisetum divisum (Gmel.) Henr. are drought-resistant $\mathrm{C}_{4}$ perennial grasses that are widely distributed in the desert of Kuwait (Batanouny, 2002). P. turgidum prefers to grow in depressions and shallow wadis with more coarse textured sandy and gravelly soil, whereas $P$. divisum prefers to grow in shallow wadis and runnels in deep sandy soil (Hegazy and Lovett-Doust, 2016). Both species are important sources of fodder for camels and sheep due to their high nutritional values (Asharf, 2006; Rafay et al., 2013). Therefore, they could be the perfect choices for sustainable forage production. In addition, these species could be used to restore and rehabilitate rangelands or to enhance their productivities (Peacock et al., 2003; El-Keblawy, 2013). Both P. turgidum and P. divisum have also been prioritized for sustainable landscaping because these species have the ability to stabilize the loose soil and therefore they could be used to protect the soil from erosion caused by wind and water (Akhter and Arshad, 2006).

Propagation of any species can only be achieved by selection of superior populations. Therefore, screening the best seed source for certain specific environment is desirable to achieve the maximum productivity (Loha et al., 2009). However, such information is lacking for most of the native desert species including $P$. turgidum and $P$. divisum. Previous studies have shown that seeds of $P$. turgidum and $P$. divisum have physiological dormancy and thus they required after-ripening (Al-Shamsi, 2009; El-Keblawy, 2013). Effects of various environmental factors (i.e., temperature, light and salt stress) and different dormancy regulating hormones have been tested on seed germination of $P$. turgidum and $P$. divisum using seeds from a single population (El-Keblawy, 2004, 2011, 2013; Al-Khateeb, 2006; Taisan, 2010). However, inter-population variability in these species was not evaluated until now. In the present study, we hypothesized that seeds collected from different populations of $P$. turgidum and $P$. divisum with similar climatic conditions will have similar germination behavior. To test this hypothesis, we examined the following questions: (i) is there a difference in seed mass according to the seed provenance? (ii) are there any light and temperature mediated mechanisms affecting germination under laboratory conditions? and (iii) is there a different response of seed germination to light and temperature according to the seed provenance?

\section{Materials and methods}

\subsection{Seed collection and seed mass measurement}

The climate is characterized by a long, dry and hot summer, with daytime temperature exceeding $50^{\circ} \mathrm{C}$ (Annual Statistical Report, 2006) in Kuwait. Mean annual precipitation is less than $114 \mathrm{~mm}$, mostly occurring during winter (Omar et al., 2007). Ripe seeds of P. turgidum and P. divisum were collected from different populations in the desert of Kuwait in May 2017 (Table 1). Seeds were 
collected from 25 to 30 randomly chosen plants for both species from each population. Seeds of both species were immediately tested for germination within a week after collection. The seed mass of each population was determined by weighing 25 seeds with three replicates.

Table 1 Population codes and habitat details of Panicum turgidum and Pennisetum divisum

\begin{tabular}{|c|c|c|c|}
\hline \multirow{2}{*}{ Population } & Code & GPS coordinates & Associated species \\
\hline & \multicolumn{3}{|c|}{ Panicum turgidum } \\
\hline $\begin{array}{c}\text { KISR (Kuwait } \\
\text { Institute for Scientific } \\
\text { Research) }\end{array}$ & KISR & $29^{\circ} 09^{\prime} 50^{\prime \prime} \mathrm{N} ; 47^{\circ} 41^{\prime} 24^{\prime \prime} \mathrm{E}$ & Pure stand \\
\hline Near Julaia & NJ & $28^{\circ} 56^{\prime} 10^{\prime \prime} \mathrm{N} ; 48^{\circ} 11^{\prime} 21^{\prime \prime} \mathrm{E}$ & $\begin{array}{l}\text { Heliotropium bacciferum, Cenchrus ciliaris and Pennisetum } \\
\text { divisum }\end{array}$ \\
\hline Sulaibia & SNB & $29^{\circ} 06^{\prime} 43^{\prime \prime} \mathrm{N} ; 47^{\circ} 24^{\prime} 51^{\prime \prime} \mathrm{E}$ & $\begin{array}{l}\text { Cyperus conglomeratus, Plantago boissieri and Calligonum } \\
\text { comosum }\end{array}$ \\
\hline $\begin{array}{l}\text { Saad Al Abdulla Al } \\
\text { Sabah road }\end{array}$ & SAA & $29^{\circ} 24^{\prime} 15^{\prime \prime} \mathrm{N} ; 47^{\circ} 41^{\prime} 37^{\prime \prime} \mathrm{E}$ & $\begin{array}{l}\text { Lasiurus sindicus, Stipagrostis plumosa, Polycarpae arepens } \\
\text { and Cyperus conglomeratus }\end{array}$ \\
\hline \multicolumn{4}{|c|}{ Pennisetum divisum } \\
\hline KISR & KISR & $29^{\circ} 07^{\prime} 42^{\prime \prime} \mathrm{N} ; 47^{\circ} 43^{\prime} 07^{\prime \prime} \mathrm{E}$ & Pure stand \\
\hline Sulaibia & SNB & $29^{\circ} 06^{\prime} 44^{\prime \prime} \mathrm{N} ; 4^{\circ} 24^{\prime} 52^{\prime \prime} \mathrm{E}$ & $\begin{array}{l}\text { Plantago boissieri, Cyperus conglomeratus and Calligonum } \\
\text { comosum }\end{array}$ \\
\hline Al Liyah-1 & AL1 & $28^{\circ} 53^{\prime} 19^{\prime \prime N} ; 48^{\circ} 14^{\prime} 27^{\prime \prime} \mathrm{E}$ & $\begin{array}{l}\text { Deverra triradiata, Panicum turgidum and Halothamnus } \\
\text { iraqensis }\end{array}$ \\
\hline Al Liyah-2 & AL2 & $28^{\circ} 55^{\prime} 38^{\prime \prime N} ; 48^{\circ} 12^{\prime} 07^{\prime \prime} \mathrm{E}$ & $\begin{array}{l}\text { Salsola imbricata, Cyperus conglomeratus and Aeluropus } \\
\text { lagopoides }\end{array}$ \\
\hline $\begin{array}{l}\text { Saad Al Abdulla Al } \\
\text { Sabah road }\end{array}$ & SAA & $29^{\circ} 24^{\prime} 05^{\prime \prime} \mathrm{N} ; 47^{\circ} 38^{\prime} 24^{\prime \prime} \mathrm{E}$ & $\begin{array}{l}\text { Cornulaca monacantha, Panicum turgidum and Haloxylon } \\
\text { salicornicum }\end{array}$ \\
\hline
\end{tabular}

Note: Population codes are the same explained in Figures 1, 3 and 4 and Table 2.

\subsection{Soil physical and chemical properties}

Soil samples were randomly collected from each population at $10 \mathrm{~cm}$ soil depth. Soil $\mathrm{pH}$ and soil electrical conductivity (EC) were determined by the saturated paw method (AFNOR, 1987). Organic matter (OM) was determined by the partial oxidation method (Walkley and Black, 1934). Furthermore, soil samples were analyzed for total nitrogen (TN), available phosphorus (AP), potassium $(\mathrm{K})$, sodium $(\mathrm{Na})$, calcium $(\mathrm{Ca})$, magnesium $(\mathrm{Mg})$, chloride $(\mathrm{Cl})$ and sulphate $\left(\mathrm{SO}_{4}\right)$. TN was determined by the Kjeldahl method, AP was extracted with $0.5 \mathrm{~N} \mathrm{NaHCO}_{3}, \mathrm{Ca}$ and $\mathrm{Mg}$ were determined by atomic absorption spectrophotometry, $\mathrm{Na}$ and $\mathrm{K}$ were determined by flame photometer, $\mathrm{Cl}$ was determined by silver nitrate titration and $\mathrm{SO}_{4}$ were determined by standard gravimetric methods. All of these methods are referenced from Jackson (1973) and Allen et al. (1986).

\subsection{Seed germination}

For the tested population of each species (4 populations for $P$. turgidum and 5 populations for $P$. divisum; Table 1), germination percentage was evaluated using 25 seeds with four replicates at night/day temperatures of $15^{\circ} \mathrm{C} / 20^{\circ} \mathrm{C}$ and $20^{\circ} \mathrm{C} / 30^{\circ} \mathrm{C}$ under the following light conditions: continuous darkness or $12 \mathrm{~h} / 12 \mathrm{~h}$ light/dark. These temperature regimes were chosen because they are close to the natural climate conditions during February and April in Kuwait (Omar et al., 2007). In the dark treatment, the Petri-dishes were wrapped with two layers of aluminum foil (Parafilm, Sigma-Aldrich, UK). The germination was conducted in 9-cm tight-fitting Petri-dishes containing one disk of filter paper (Whatman No. 1), moistened with distilled water. Seeds were considered to be germinated after the cotyledons appeared. Germinated seeds were counted and removed every alternate day until $28 \mathrm{~d}$. Germinated seeds in the dark treatment were counted after $28 \mathrm{~d}$. A seed was considered to be viable when a cross-section showed that the endosperm was white and appeared healthy. A cut-test was performed to test the embryo status under a binocular microscope that is used to evaluate the viability of un-germinated seeds at the end of germination experiment. 


\subsection{Data analysis}

For these two species, the seed mass was analyzed as a function of seed provenance with a Kruskal-Wallis test. The germination of both species was analyzed as a function of population (P) and incubation conditions, i.e., light (L) and temperature $(\mathrm{T})$ with generalized linear models. The mean germination time (MGT) of both species was analyzed as a function of $\mathrm{P}$ and $\mathrm{T}$ with generalized linear models and Gaussian error structures in R version 3.3.2 (R Core Team, 2016). Meanwhile, chi-square tests were performed to make sure that the model fit did not significantly decrease.

\section{Results}

\subsection{Seed mass}

The seed masses of both species strongly varied according to their seed provenances. The heavier seeds of $P$. turgidum were produced in population KISR and the lighter seeds in population NJ (chi-square=8.195, $d f=3, P=0.042$ ). On the other hand, the heavier seeds of $P$. divisum were produced in population SAA and the lighter in population SNB (chi-square $=10.126, d f=4$, $P=0.038$; Fig. 1). Both species produced the heavier seeds in population with a higher soil EC (Fig. 2; Table 2).
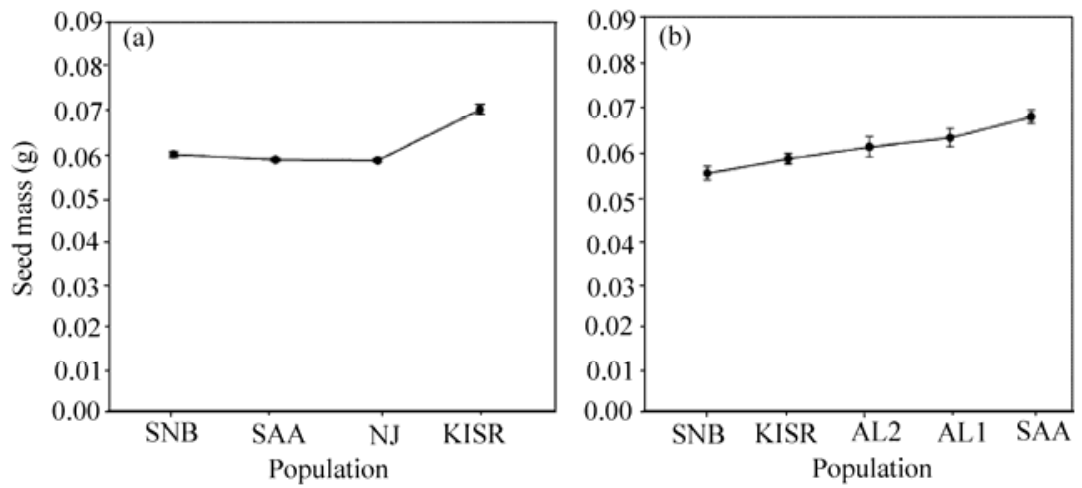

Fig. 1 Seed masses of P. turgidum (a) and P. divisum (b) in different populations. Bars indicate standard errors.

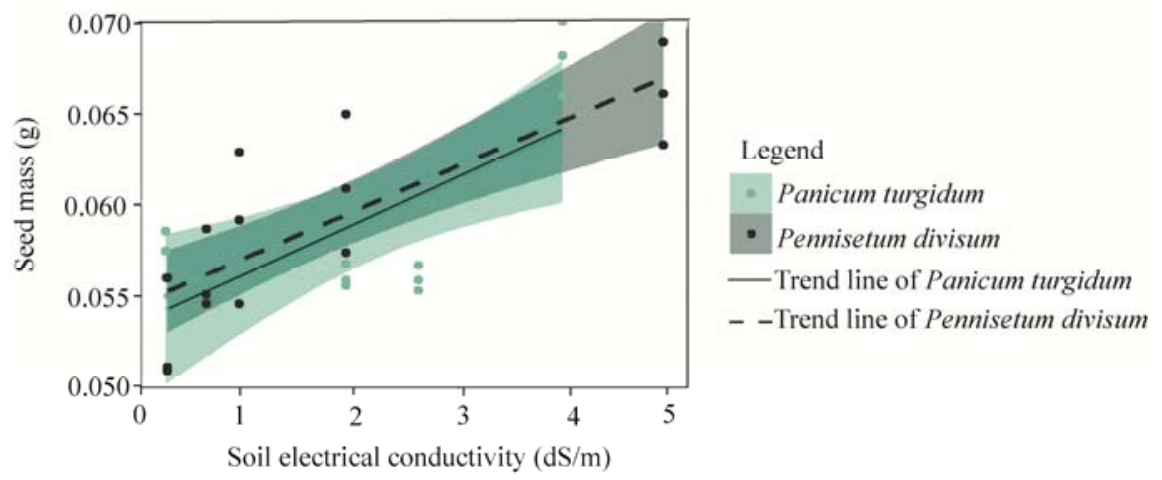

Fig. 2 Seed masses of $P$. turgidum and $P$. divisum along a gradient of soil electrical conductivity

\subsection{Germination percentage}

Both species showed a strong and significant variation in germination percentage among different seed provenances. Differences of $31.7 \%$ and $20.7 \%$ were detected between the population with the highest germination and the population with the lowest germination of $P$. turgidum and $P$. divisum, respectively (Fig. 3). The highest germination percentage was recorded in population SAA and the lowest in population KISR for $P$. turgidum, while, for $P$. divisum the highest 
Table 2 Soil characteristics of $P$. turgidum and P. divisum in different populations

\begin{tabular}{|c|c|c|c|c|c|c|c|c|c|c|c|}
\hline \multirow[t]{2}{*}{ Population } & $\mathrm{pH}$ & $\begin{array}{c}\mathrm{EC} \\
(\mathrm{dS} / \mathrm{m}) \\
\end{array}$ & $\begin{array}{c}\mathrm{TN} \\
(\mathrm{mg} / \mathrm{kg})\end{array}$ & $\begin{array}{c}\text { AP } \\
(\mathrm{mg} / \mathrm{kg})\end{array}$ & $\begin{array}{c}\mathrm{Ca} \\
(\mathrm{mg} / \mathrm{kg})\end{array}$ & $\begin{array}{c}\mathrm{Mg} \\
(\mathrm{mg} / \mathrm{kg})\end{array}$ & $\begin{array}{c}\mathrm{Na} \\
(\mathrm{mg} / \mathrm{kg})\end{array}$ & $\begin{array}{c}\mathrm{K} \\
(\mathrm{mg} / \mathrm{kg})\end{array}$ & $\begin{array}{c}\mathrm{Cl} \\
(\mathrm{mg} / \mathrm{kg})\end{array}$ & $\begin{array}{c}\mathrm{SO}_{4} \\
(\mathrm{mg} / \mathrm{kg})\end{array}$ & $\begin{array}{l}\text { OM } \\
(\%)\end{array}$ \\
\hline & \multicolumn{11}{|c|}{ Panicum turgidum } \\
\hline KISR & 7.7 & 3.830 & 360 & 33.0 & 141.0 & 30.6 & 57.8 & 35.4 & 161.3 & 176.1 & 0.80 \\
\hline NJ & 8.1 & 2.670 & 100 & 2.8 & 72.1 & 8.1 & 42.2 & 5.5 & 75.0 & 148.3 & 0.29 \\
\hline SNB & 8.0 & 0.640 & 95 & 3.0 & 24.9 & 2.7 & 2.0 & 5.8 & 5.1 & 23.6 & 0.25 \\
\hline \multirow[t]{2}{*}{ SAA } & 7.6 & 2.088 & 110 & 8.6 & 81.1 & 5.7 & 19.1 & 15.0 & 58.5 & 122.0 & 0.44 \\
\hline & \multicolumn{11}{|c|}{ Pennisetum divisum } \\
\hline KISR & 7.8 & 0.965 & 540 & 12.8 & 49.5 & 3.4 & 17.1 & 9.1 & 24.8 & 64.4 & 1.16 \\
\hline SNB & 7.8 & 0.656 & 160 & 3.8 & 25.8 & 0.4 & 4.9 & 5.0 & 8.1 & 20.1 & 0.42 \\
\hline AL1 & 7.6 & 2.088 & 110 & 8.6 & 81.1 & 5.7 & 19.1 & 15.0 & 58.5 & 122.0 & 0.44 \\
\hline AL2 & 7.8 & 1.230 & 220 & 11.2 & 39.4 & 4.7 & 15.4 & 4.8 & 28.5 & 68.7 & 0.92 \\
\hline SAA & 7.4 & 4.640 & 115 & 12.2 & 144.2 & 21.5 & 80.9 & 21.1 & 63.3 & 326.0 & 0.30 \\
\hline
\end{tabular}

Note: EC, electrical conductivity; TN, total nitrogen; AP, available phosphorus; $\mathrm{Ca}$, calcium; Mg, magnesium; Na, sodium; K, potassium; $\mathrm{Cl}$, chloride; $\mathrm{SO}_{4}$, sulphate; $\mathrm{OM}$, organic matter.
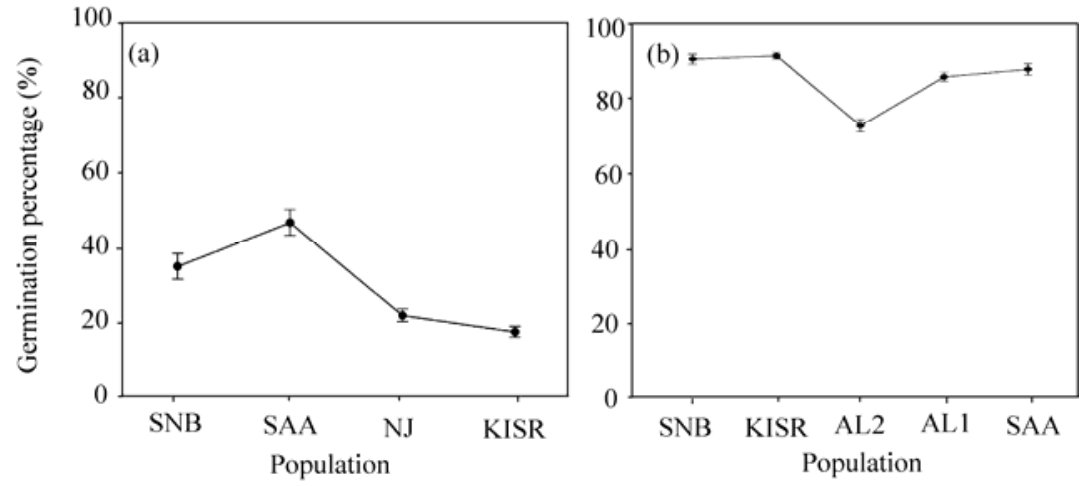

Fig. 3 Germination percentages of P. turgidum (a) and P. divisum (b) in different populations. Bars indicate standard errors.

germination percentage was found in population KISR and the lowest in population AL2 (Fig. 3). Germination percentage of $P$. turgidum was significantly influenced by temperature (Table 3 ). Germination percentage of $P$. trugidum was $15.0 \%$ higher at high temperature $\left(20^{\circ} \mathrm{C} / 30^{\circ} \mathrm{C}\right)$ than at low temperature $\left(15^{\circ} \mathrm{C} / 20^{\circ} \mathrm{C}\right.$; Fig. $\left.4 \mathrm{a}\right)$. On the other hand, germination percentage of $P$. divisum was influenced by light, as slightly higher germination was found under cycle of light and darkness than under complete darkness (Table 3).

Table 3 Effects of population (P), temperature (T) and light (L) and their interactions on seed germinations of P. turgidum and P. divisum

\begin{tabular}{|c|c|c|c|c|c|c|}
\hline \multirow{2}{*}{ Treatment } & \multicolumn{3}{|c|}{ Panicum turgidum } & \multicolumn{3}{|c|}{ Pennisetum divisum } \\
\hline & $d f$ & LRT & $P$ & $d f$ & LRT & $P$ \\
\hline $\mathrm{P}$ & 3 & 120.631 & $2.2 \mathrm{e}-16^{* * *}$ & 4 & 86.198 & $<2 \mathrm{e}-16^{* * *}$ \\
\hline $\mathrm{T}$ & 1 & 45.902 & $1.243 \mathrm{e}-11^{* * *}$ & 1 & 4.862 & $0.738^{\mathrm{ns}}$ \\
\hline $\mathrm{L}$ & 1 & 0.842 & $0.359^{\mathrm{ns}}$ & 1 & 4.862 & $0.028^{*}$ \\
\hline $\mathrm{T} \times \mathrm{L}$ & 1 & 0.012 & $0.901^{\mathrm{ns}}$ & 1 & 0.000 & $0.994^{\mathrm{ns}}$ \\
\hline $\mathrm{P} \times \mathrm{L}$ & 3 & 2.713 & $0.438^{\mathrm{ns}}$ & 4 & 4.655 & $0.325^{\text {ns }}$ \\
\hline $\mathrm{P} \times \mathrm{T}$ & 3 & 8.873 & $0.031^{*}$ & 4 & 9.476 & $0.049^{*}$ \\
\hline $\mathrm{P} \times \mathrm{T} \times \mathrm{L}$ & 3 & 3.315 & $0.346^{\mathrm{ns}}$ & 4 & 0.509 & $0.973^{\text {ns }}$ \\
\hline
\end{tabular}

Note: df, degree of freedom; LRT, likelihood ratio test; ${ }^{\text {ns }}$, not significant; ${ }^{*}$, significances at $P<0.05$ level; ${ }^{* * *}$, significances at $P<0.001$ level.

Germination percentage of both species was significantly influenced by the interaction between 
population and temperature (Table 3). For P. turgidum, a difference of $45.0 \%$ in germination percentage was found between population SAA and population KISR at high and low temperatures; meanwhile, $P$. divisum showed a difference of $23.5 \%$ between population KISR and population AL2 at high and low temperatures (Figs. 4a and b). The difference in P. turgidum germination decreased when soil EC increased. Germination percentage of $P$. turgidum population with a high soil EC was almost equal under both temperature regimes (Table 2; Fig. 4). Conversely, no clear pattern related with soil EC was observed in germination percentage of P. divisum (Fig. 2). Finally, when comparing the variation in seed mass and germination percentage according to the seed provenance, no clear relationship among these traits was found (Figs. 1 and 3).

\subsection{Mean germination time (MGT)}

MGT was significantly influenced by the seed provenance (Table 4). MGT of P. turgidum in population SNB was $5.76 \mathrm{~d}$, while it was $4.77 \mathrm{~d}$ in population NJ. On the other hand, values of MGT of $P$. divisum in population AL2 and population KISR were 2.47 and $2.25 \mathrm{~d}$, respectively (Fig. 4). Additionally, the interaction between population and temperature was significant for both species. MGT of $P$. turgidum was $6.04 \mathrm{~d}$ in population SNB at low temperature, while it was $4.14 \mathrm{~d}$ in population NJ at high temperature. On the other hand, for $P$. divisum it was $2.49 \mathrm{~d}$ in population AL2 at low temperature and $2.33 \mathrm{~d}$ in population AL1 at high temperature (Figs. 4c and d).

Table 4 Effects of population (P) and temperature (T) and their interaction on mean germination time of $P$. turgidum and $P$. divisum

\begin{tabular}{ccccc}
\hline Species & Treatment & df & Scaled deviation & $P$ \\
\hline \multirow{2}{*}{ Panicum turgidum } & $\mathrm{P}$ & 3 & 10.343 & $0.016^{*}$ \\
& $\mathrm{~T}$ & 1 & 2.894 & $0.122^{\mathrm{ns}}$ \\
& $\mathrm{P} \times \mathrm{T}$ & 3 & 11.173 & $0.011^{*}$ \\
Pennisetum divisum & $\mathrm{P}$ & 4 & 38.522 & $8.745 \mathrm{e}-08^{* * *}$ \\
& $\mathrm{~T}$ & 1 & 0.029 & $0.865^{\mathrm{ns}}$ \\
& $\mathrm{P} \times \mathrm{T}$ & 4 & 11.082 & $0.026^{*}$ \\
\hline
\end{tabular}

Note: $d f$, degree of freedom; ${ }^{\text {ns }}$, not significant; ${ }^{*}$, significances at $P<0.05$ level; ${ }^{* * *}$, significances at $P<0.001$ level.
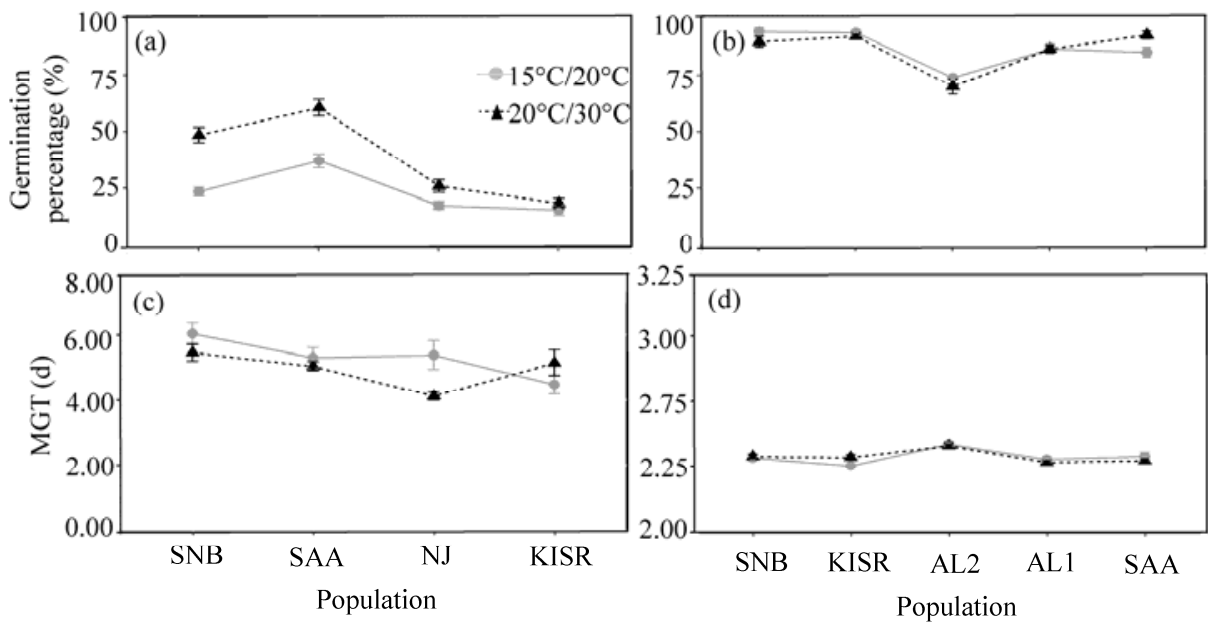

Fig. 4 Germination percentages and mean germination time (MGT) of P. turgidum (a and c) and P. divisum (b and d) in different populations and temperatures. Bars indicate standard errors.

\section{Discussion}

Knowledge of variability among populations is essential for planning effective strategies for germplasm collection destined to conservation and restoration (Eriksson, 2014). In the 
study, seeds collected from different populations of $P$. turgidum and $P$. divisum showed considerable inter-population variation in seed mass. Difference in seed mass within a species has important ecological consequences because seed mass can affect seed water relation, seed dispersal, germination percentage and seedling establishment (Zhang and Maun, 1990). Maternal environmental conditions such as climatic conditions, soil nutrients and soil moisture content play important roles in determining seed mass (Quesada et al., 1996; Wright et al., 1999; Tremayne and Richards, 2000). Considering that the seeds of $P$. turgidum and $P$. divisum were collected from populations with similar climatic conditions, it is possible that the variation in resource availability among different populations or genetic characteristics of seed provenance could be responsible for the variability in seed mass of both species. Among the studied soil chemical properties, only soil EC shows an apparent positive relationship with seed mass of both species. EC is an indicator of soil salinity and generally, in salt-affected soils, nutrient uptake and use efficiency of plant are low due to this source of stress (Fageria et al., 2011). Therefore, we assumed that the species growing in high saline habitat might allocate more resources to the reproduction and hence the seeds collected from slightly high saline habitat have a higher seed mass. For example, Boot et al. (1986) and Steyn et al. (1996) found that plants can alter the resource allocation to growth and reproduction under environmental stress. In the study, $P$. turgidum seeds that were collected from populations with a high soil EC, germinated equally under both temperature regimes, indicating that seeds collected from similar habitats may have similar temperature requirements during seed germination. The germination percentage strongly varied among populations of $P$. turgidum $(17 \%-49 \%)$ and $P$. divisum $(72 \%-93 \%)$. These variations in germination percentage among populations are not rare. Previous studies highlighted that seeds from different populations of desert species such as Anabasis setifera, Centaurium somedanum, Helianthemum salicifolium and Suaeda aegyptiaca can vary in their dormancies and germinations (Fernández-Pascual et al., 2013; El-Keblawy et al., 2016; Yeşilyurt et al., 2017). Such variations in dormancy and germination among populations have been linked with the ability of species to persist under variable environmental conditions by producing seeds with different dormancy status, thus reducing the risk of synchronizing germination and increasing the fitness for germination under various environmental conditions (Cochrane et al., 2015; Santo et al., 2015). Previous studies reported that $P$. turgidum and $P$. divisum exhibit different levels of physiological dormancy (Al-Shamsi, 2009; El-Keblawy, 2013). Considering the strong variation in germination percentage among populations reported here, we suggest that no conclusions regarding germination of these species could be drawn. Moreover, the seed provenance needs to be carefully considered before interpreting the germination behaviour in wild species because this information could help in understanding the survival strategies of species growing under unpredictable environmental conditions (Gutterman, 1994; Kigel, 1995).

In the present study, germination percentage of both species varied according to the seed provenance and the temperature. $P$. turgidum seeds showed a better germination at high temperature $\left(20^{\circ} \mathrm{C} / 30^{\circ} \mathrm{C}\right)$ irrespective of seed provenance. These results are in contradiction with Al-Khateeb (2006) and Al-Shamsi (2009), who reported that P. turgidum germinated well in a wide range of temperatures. In addition, light requirement for optimal germination of $P$. turgidum appeared to vary in each population, implying the inter-population sensitivity to light.

For $P$. turgidum, complete darkness seems to be more effective in enhancing germination at high temperature, which might be an adaptive strategy for desert conditions. If the seeds are remained on the surface layer, they would face strong light, extreme temperatures and drought due to the high evaporation at surface layer, and these factors could, cumulatively, inhibit seedling establishment. Seeds of $P$. divisum germinated well in both light and dark, indicating that light is not an obligatory requirement for germination. Furthermore, the ability of $P$. divisum to germinate in dark could be related to its adaptability to sandy habitat where sand burial often occurs. However, if they are buried too deep in the soil, they might be negatively impacted because they might spend all their reserves to reach the soil surface. Understanding the ideal conditions for seed germination, including temperature, is essential for determining the timing of seed sowing for vegetation restoration (Baskin and Baskin, 2014; Dürr et al., 2015). Likewise, 
light requirements for germination could provide indications about the capacity of the species to form soil seed banks and also provide information about the appropriate sowing method (Jones et al., 2004; Bhatt and Pérez-García, 2016).

MGT of both species varied according to the seed provenance. Additionally, MGT for different populations of both $P$. turgidum and $P$. divisum showed variations at different temperatures. This result might be important for these species' regeneration in the field because seeds from certain provenance might exhibit faster germination in the earlier season by taking advantage of earlier rain events (January-February), whereas seeds of other populations may germinate in the later season (during March-April). Seed mass did not have any effect on germination percentage and MGT of both two species. These findings are in agreement with Baskin and Baskin (2014), who reported that germination rate and percentage could increase, decrease or remain unaffected by the difference in seed size.

Inter-population variability in seed mass, germination percentage and MGT has been correlated with the differences in environmental conditions, biotic and abiotic factors, as well as genetic factors (Bewley and Black, 1994; Li and Foley, 1997; Baskin and Baskin, 2014). Although different populations of $P$. turgidum and $P$. divisum experience similar climatic conditions during seed production, these populations might differ in terms of herbivory pressure, inter- and intra-specific competition with respect to soil nutrients and water holding capacity that could be responsible for the observed variation in seed mass and seed germination percentage among populations of both species. However, we cannot confirm that there were genetic differences among populations in germination because our study only evaluates the response to seed provenance.

The variability in germination behavior among populations of $P$. turgidum and $P$. divisum might be advantageous under harsh desert environments, which could favor the establishment of seedlings. Therefore, we suggest that this high variation among seed provenances must be adequately managed and could be useful in identifying the best seed sources for vegetation restoration.

\section{Conclusions}

This study indicates that $P$. turgidum seeds could germinate from March to early April, the period when the monthly average temperatures ranged from $18^{\circ} \mathrm{C}$ to $34^{\circ} \mathrm{C}$ in Kuwait (data not shown). However, seeds of $P$. divisum could be sown at any time when there is a possibility of rain. Our study also confirms that inter-population variation in seed traits was found in both species and could be useful for vegetation restoration and management. However, field studies will be necessary to resolve the adaptive effects of phenotypes of species.

\section{Acknowledgements}

This work was supported by the Kuwait Institute for Scientific Research (KISR). We would also like to thank Dr. Ashok Kumar ALVA and Dr. Samuel C ALLEN for the linguistic revision of the manuscript.

\section{References}

AFNOR. 1987. Collection of French Standards, Soil Quality, Methods of Analysis. France: French Standards Association Afnor, 31-147. (in French)

Akhter R, Arshad M. 2006. Arid rangelands in the Cholistan Desert (Pakistan). Sécheresse, 17(1-2): 210-217.

Al-Awadhi J M, Misak R F, Omar S S. 2003. Causes and consequences of desertification in Kuwait: a case study of land degradation. Bulletin of Engineering Geology and the Environment, 62(2): 107-115.

Al-Khateeb S A. 2006. Effect of salinity and temperature on germination, growth and ion relations of Panicum turgidum Forssk. Bioresource Technology, 97(2): 292-298.

Allen S E, Grimshaw H M, Rowland A P. 1986. Chemical analysis. In: Moore P D, Chapman S B. Methods in Plant Ecology. London: Blackwell Scientific Publication, 285-344. 
Al-Shamsi N. 2009. Germination ecology of two indigenous range grasses Lasiurus scindicus and Panicum turgidum. MSc

Thesis. Al-Ain: UAE University.

Al-Taisan W A. 2010. Comparative effects of drought and salt stress on germination and seedling growth of Pennisetum divisum (Gmel.) Henr. American Journal of Applied Sciences, 7(5): 640-646.

Annual Statistical Report. 2006. Ministry of Planning. Kuwait: Kuwait Central Statistical Bureau, 518.

Ashraf M. 2006. Tolerance of some potential forage grasses from arid regions of Pakistan to salinity and drought. In: Öztürk M, Waisel Y, Khan M A, et al. Biosaline Agriculture and Salinity Tolerance in Plants. Birkhäuser: Basel, 15-27.

Baskin C C, Baskin J M. 2014. Seeds: Ecology, Biogeography, and Evolution of Dormancy and Germination ( $2^{\text {nd }}$ ed.). San Diego: Academic Press, 1600.

Batanouny K H. 2002. Biodiversity strategy and rangelands in the Arab world. In: Hamzah R, Alaa El-Din M N, Mohammed S A. National Biodiversity Planning in the Arab World. Bahrain: Arabian Gulf University Publication, 121-142.

Bewley J D, Black M. 1994. Dormancy and the control of germination In: Bewley J D, Black M. Seeds. USA: Springer, 199-271.

Bhatt A. 2013. Propagation of potential native plants for urban landscape in Gulf countries. In: Qatar Foundation Annual Research Forum Proceeding. Qatar: Hamad bin Khalifa University Press, EEP 06.

Bhatt A, Pérez-García F. 2016. Seed dormancy of Ochradenus baccatus (Resedaceae), a shrubby species from Arabian Desert regions. Revista de Bbiologia Tropical, 64(3): 965-974.

Bhatt A, Phondani P C, Pompelli M F. 2016. Seed maturation time influences the germination requirements of perennial grasses in desert climate of Arabian Gulf. Saudi Journal of Biological Sciences, 25(8): 1562-1567.

Boot R, Raynal D J, Grime J P. 1986. A comparative study of the influence of drought stress on flowering in Urtica dioica and U. urens. Journal of Ecology, 74(2): 485-495.

Carón M M, De Frenne P, Brunet J, et al. 2014. Latitudinal variation in seeds characteristics of Acer platanoides and A. pseudoplatanus. Plant Ecology, 215(8): 911-925.

Cochrane A, Yates C J, Hoyle G L, et al. 2015. Will among population variation in seed traits improve the chance of species persistence under climate change? Global Ecology and Biogeography, 24(1): 12-24.

Dürr C, Dickie J B, Yang X Y, et al. 2015. Ranges of critical temperature and water potential values for the germination of species worldwide: contribution to a seed trait database. Agricultural and Forest Meteorology, 200: 222-232.

El-Keblawy A. 2004. Salinity effects on seed germination of the common desert range grass, Panicum turgidum. Seed Science and Technology, 32: 873-878.

El-Keblawy A, Al-Ansari F, Al-Shamsi N. 2011. Effects of temperature and light on salinity tolerance during germination in two desert glycophytic grasses, Lasiurus scindicus and Panicum turgidum. Grass and Forage Science, 66(2): $173-182$.

El-Keblawy A. 2013. Impacts of dormancy regulating chemicals on innate and salinity-induced dormancy of four forage grasses native to Arabian deserts. Grass and Forage Science, 68(2): 288-296.

El-Keblawy A, Gairola S, Bhatt A. 2016. Maternal salinity environment affects salt tolerance during germination in Anabasis setifera: A facultative desert halophyte. Journal of Arid Land, 8(2): 254-263.

El-Keblawy A, Gairola S, Bhatt A, et al. 2017. Effects of maternal salinity on salt tolerance during germination of Suaeda aegyptiaca: a facultative halophyte in the Arab Gulf desert. Plant Species Biology, 32(1): 45-53.

Eriksson G. 2014. Collection of propagation material in the absence of genetic knowledge. In: Bozzano M, Jalonen R, Thomas E, et al. Genetic Considerations in Ecosystem Restoration Using Native Tree Species. State of the World's Forest Genetic Resources-Thematic Study. Rome: FAO and Biodiversity International, 79-84.

Fageria N K, Gheyi H R, Moreira A. 2011. Nutrient bioavailability in salt affected soils. Journal of Plant Nutrition, 34(7): 945-962.

Fernández-Pascual E, Jiménez-Alfaro B, Caujapé-Castells J, et al. 2013. A local dormancy cline is related to the seed maturation environment, population genetic composition, and climate. Annals of Botany, 112(5): 937-945.

Gutterman Y. 1994. Strategies of seed dispersal and germination in plants inhabiting deserts. Botanical Review, 60(4): $373-425$.

Hegazy A, Lovett-Doust J. 2016. Plant Ecology in the Middle East. Oxford: Oxford University Press, 339.

Jackson M L. 1973. Soil Chemical Analysis. New Delhi, India: Prentice Hall, 521.

Jones K L, Roundy B A, Shaw N L, et al. 2004. Environmental effects on germination of Carex utriculata and Carex nebrascensis relative to riparian restoration. Wetlands, 24(2): 467-479.

Kigel J. 1995. Seed Development and Germination. New York: Marcel Dekker INC., 872.

Li B, Foley M E. 1997. Genetic and molecular control of seed dormancy. Trends in Plant Sciences, 2(10): 384-389. 
Loha A, Tigab M, Fries A. 2009. Genetic variation among and within populations of Cordia africana in seed size and germination responses to constant temperatures. Euphytica, 165: 189.

Mganga K Z, Musimba N K R, Nyariki D M, et al. 2015. The choice of grass species to combat desertification in semi-arid Kenyan rangelands is greatly influenced by their forage value for livestock. Grass and Forage Science, 70(1): $161-167$.

Omar S A S, Al-Mutawa Y, Zaman S. 2007. Vegetation of Kuwait. Kuwait: Kuwait Institute for Scientific Research, 47-89.

Osman A E, Makawi M, Ahmed R. 2008. Potential of the indigenous desert grasses of the Arabian Peninsula for forage production in a water-scarce region. Grass and Forage Science, 63(4): 495-503.

Peacock J M F, Erguson M E, Alhadrami G A, et al. 2003. Conservation through utilization: a case study of the indigenous forage grasses of the Arabian Peninsula. Journal of Arid Environments, 54(1): 15-28.

Phondani P C, Bhatt A, Elsarrag E, et al. 2016. Criteria and indicator approach of global sustainability assessment system for sustainable landscaping using native plants in Qatar. Ecological Indicators, 69: 381-389.

Quesada M, Winsor J A, Stephenson A G.1996. Effects of pollen selection on progeny vigour in a Cucurbita pepo $\times$ C. texana hybrid. Theoretical and Applied Genetics, 92(7): 885-890.

R Core Team. 2016. R: A Language and Environment for Statistical Computing. Vienna: R Foundation for Statistical Computing. [2018-06-07]. http://www.R-project.org.

Richer R. 2008. Conservation in Qatar. Impacts of increasing industrialization. Centre for International and Regional Studies (CIRS). Qatar: Georgetown University School of Foreign Service, 1-38.

Richer R, Bhatt A, Abdul Majid S, et al. 2016. Native plant landscaping and species selection to promote sustainability and biodiversity in Qatar. Q Science Proceedings: Qatar Green Building Conference, 2016. The Action, 41.

Santo A, Mattana E, Grillo O, et al. 2015. Morpho-colorimetric analysis and seed germination of Brassica insularis Moris (Brassicaceae) populations. Plant Biology, 17(2): 335-343.

Steyn H M, Van Rooyen N, Van Rooyen M W, et al. 1996. The phenology of Namaqualand ephemeral species-The effect of water stress. Journal of Arid Environments, 33(1): 49-62.

Tremayne M A, Richards A J. 2000. Seed weight and seed number affect subsequent fitness in outcrossing and selfing Primula species. New Phytologist, 148(1): 127-142.

Walkley A, Black I A. 1934. An examination of the Degtjareff method for determining soil organic matter, and a proposed modification of the chromic acid titration method. Soil Science, 37(1): 29-38.

Wright K J, Seavers G P, Peters N C B, et al. 1999. Influence of soil moisture on the competitive ability and seed dormancy of Sinapis arvensis in spring wheat. Weed Research, 39(4): 309-317.

Yaqoob S, Khan R A, Rafay M, et al. 2013. Nutritional evaluation of major range grasses from Cholistan Desert. Pakistan Journal of Nutrition, 12: 23-29.

Yeşilyurt E B, Erik S, Tavşanoğlu Ç. 2017. Inter-population variability in seed dormancy, seed mass and germination in Helianthemum salicifolium (Cistaceae), a hard-seeded annual herb. Folia Geobotanica, 52(2): 153-263.

Zhang J, Maun M A. 1990. Effects of sand burial on seed germination, seedling emergence, survival, and growth of Agropyron psammophilum. Canadian Journal of Botany, 68(2): 304-310. 